In this context the survey discusses the requirements of membership, the administration and management and the degree of co-operation to be achieved. As a study it is both interesting and instructive; but the simple and easy style of the writer should commend this book even to the ordinary reader.

The third book under notice is a poor attempt to propound a fundamental truth - the need for Christian ideals (brotherly relationship, the author calls it)in an economy run on business-like lines and activated by the profit motive. Some of the comments are certainly of value, but they are completely lost in the book, which is both badly written and badly printed. The reader would, indeed, have to feel very penitential to take the trouble to go through all 218 pages and winnow the chaff from the wheat.

\section{SCIENCE AND PHILOSOPHY}

Science and the Meanings of Truth

Studies Introductory to asking What is meant to-day by Physical Explanation of Nature, by Mechanisms of Cause and Effect, and by a Claim that Scientific Knowledge is True. By Dr. Martin Johnson. Pp. 179. (London: Faber and Faber, Ltd., 1946.) 128. 6d. net.

A $\mathrm{S}$ may be gathered from its sub-title, the central A theme of this book is an examination of the meanings which have been or may be given to the word 'truth' in relation to recent developments in physics.

"Until the era of some recent researches in atomics and relativity, the advances of science were satisfactorily carried forward by alternation of simple hypothesis and experimental test; the quantities mentioned in the former were not unlike those measured in the latter, the nature of hypothesis being restricted to a certain kind which had served adequately from the Renaissance. In particular, the success of early modern astronomy, in replacing geometrical description of planetary motion as imaginary combinations of circles, by actual elliptic orbits linked causally with a theory of gravitation, had set a type of hypothesis in which a cause was assigned for activating a mechanical model or mental picture. In later uses of this kind of picture, the criterion of truth to be tested by experiment was whether the supposed and imperceptible substances underlying perceivable phenomena act in accord with the Newtonian laws found adequate for the behaviour of visible and tangible objects. Striking success followed the exploitation of this eriterion of truth in the theory of gases and of heat, and the electromagnetic theory of light, and some of the simpler theory of metals."

But with recent researches in physics, this idea of cause in the sense of "forces causing changes in motion" broke down, because it became impossible to construct mechanical models. Such models have, in fact, been recognized as concepts, and scientific knowledge regarded as a system of formal relations instead of a correspondence with any external world imagined in a model.

After reviewing briefly the meanings of truth implied in the writings of Heisenberg, Dirac, Eddington, Milne, Whitehead and Russell, Dr. Johnson puts forward a view of his own. For him science rests on the postulate that Nature is intelli- gible, and the essential fact underlying this is for him that scientific knowledge is communicable. That is, first, after measurements have been made propositions are formulated in such a way that the results are repeatable and therefore verifiable; secondly, such statements are further judged by 'coherence' in the sense of correlating the widely different physical situations within each of which communicability has already guaranteed a degree of truth. For example, the conic sections which replaced the medieval circles in describing planetary motions could also describe the orbits of comets and were a valuable though transient help in the supposed orbits of electrons within the atom. This criterion of truth is thus a practical one-."coherence between communicable patterns of measurement". We no longer ask whether the 'wave-electron' or the 'particleelectron' are true or false "in the sense of corresponding to any permanent object with the model properties of anyone's mental picture or concept"; each theory is simultaneously 'true' as "each is communicable over its own range of physical situations".

The second part of this book is concerned with more general philosophical problems arising out of the meanings given to truth in science and in particular with the relation of the physicist's mind to the experience which comes to him from without. The discussion is confined to the types of problems arising rather than with an attempt to solve them.

This book is not easy to read, and the style is involved and not always happy. It does, however, cover many interesting topics and not its least value is that it is written by a practising physicist thinking his way through the implications of his subject.

\section{A. C. Crombie}

\section{A GUIDE TO THE ASTROLABE}

Traité de l'astrolabe

Par Henri Michel. (Ouvrage publié avec le concours de la Fondation Universitaire de Belgique.) Pp. viii $+202+24$ plates. (Paris: Gauthier-Villars, 1947.) 1,200 francs.

7 HERE are not a few treatises, old and new, that I concern themselves with that ancient and beautiful instrument, the astrolabe; but few, if any, are of use to the student or collector possessing an astrolabe who wishes to know how old it is, how it is used, and what are the principles that underly its construction. The work under review most admirably fulfils these functions, and its account of the multifarious types of astrolabe is the clearest and most reliable of those known to the reviewer.

The book is divided into two parts. The former of these deals briefly with the history of the astrolabe and goes on to a description and explanation of the various types, eastern and western. The author discounts the generally accepted ascription of the invention to Hipparchus, largely on the ground that it was not known to Ptolemy, whose astrolabon organon was something quite different from the instrument to which the name of astrolabe has been traditionally attached. He finds the first reference to this, the planispheric astrolabe, in the sixthcentury treatise of Philoponus, who tells us that his master Ammonius (c. A.D. 500) had written on the subject. M. Michel's view is clearly in accord with 